\title{
Paratenic hosts for the parasitic nematode Anguillicola crassus in Lake Balaton, Hungary
}

\author{
Cs. Székely \\ Veterinary Medical Research Institute, Hungarian Academy of Sciences, PO Box 18, H-1581 Budapest, Hungary
}

\begin{abstract}
A 1 yr study was conducted to determine which fish species may play a role in the life cycle of Anguillicola crassus in various habitats of Lake Balaton. Hungary. The prevalence and intensity of the larval infection of fish species acting as paratenic hosts was studied, and observations were made on the types of paratenic host reactions against larvae. With the exception of 1 species, all 20 fish species were infected by $A$. crassus larvae; however, the prevalence and intensity of infection varied widely. Six species (asp, white bream, Chinese rasbora, pike, river goby, European catfish), hitherto unreported as paratenic hosts, also proved to be infected by larvae in Lake Balaton. Of the 13 fish species examined in large numbers, ruffe and European catfish showed the highest prevalence of infection $(100 \%)$, followed by river goby $(83 \%)$, white bream $(79 \%)$ and bleak $(68 \%)$. Of these 13 fish species, ruffe showed the highest intensity of infection by live larvae (mean intensity: 39.3 3rd stage larvae, $L_{3}$ ), followed by European catfish (mean number of live larvae: 26.9) and river goby (mean number of live larvae: 9.1 ). The mean number of live $\mathrm{L}_{3}$ in bleak, a species regarded as the principal food source for eels, was 4.1. Specimens containing only dead or both dead and live larvae were much more common in cyprinid fishes than in species belonging to other taxonomical entities. In these fish, the process of encapsulation and subsequent necrosis of live larvae could also be observed. With knowledge of the feeding habits of eels, it appears that bleak play the most important role in the transmission of anguillicolosis. Other intensively infected fish species (e.g. ruffe) may also contribute to massive infection of individual eels, even if they have a lower share in the eels' food structure.
\end{abstract}

KEY WORDS: Eel parasite Anguillicola $\cdot$ Paratenic hosts - Lake Balaton (Hungary)

\section{INTRODUCTION}

The parasitic nematode Anguillicola crassus (Nematoda: Dracunculoidea) was brought into Europe from Southeast Asia with Japanese eel stocks imported for consumption and further breeding in the 1980 s (Peters \& Hartmann 1986). It then rapidly spread throughout the European continent from west to east (Neumann 1985, van Banning et al. 1985, Canestri-Trotti 1987 , Dekker \& van Willigen 1987, Taraschewski et al. 1987 , Dupont \& Petters 1988, Hellström et al. 1988, Koie 1988, Belpaire et al. 1989, Kennedy \& Fitch 1990, Székely et al. 1991, Cruz et al. 1992), probably as a result of insufficiently controlled live fish transportations (Belpaire et al. 1989). The original host of $A$. crassus is the Japanese eel Anguilla japonica, in which the infection does not give rise to major lesions (Egusa 1979), while in the European eel Anguilla anguilla it may give rise to severe pathological changes (van Banning \& Haenen 1989, van Willigen \& Dekker 1989 , Kamstra 1990, Molnár et al. 1993). Mortality due to anguillicolosis in cultured European eels has been described by Sarti et al. (1985), Hartmann (1987), Liewes \& Schaminee-Main (1987), Mellergaard (1988) and Boon et al. (1989). Repeated mortality caused by A. crassus in eels living in natural waters has been reported by Molnár et al. (1991, 1993) and Bíró (1992) from Lake Balaton, Hungary.

The life cycle of Anguillicola crassus was studied by De Charleroy et al. (1990). Adult A. crassus specimens live and reproduce in the swimbladder of eels. The eggs excreted by the female helminths contain 2nd stage hatching or hatched larvae which are consumed by copepods upon their release into the outside world. After moulting in the body cavity of copepods, 3rd stage larvae emerge which are infective to eels. The 
copepods containing the larvae are either consumed directly by eels which thus become infected, or serve as food source for another fish species, a so-called paratenic host. The 3rd stage larvae do not develop further in the paratenic host, or in exceptional cases develop into 4 th stage larvae.

Fish species acting as paratenic host also play a role in the feeding of eels of larger body size. According to Paulovits \& Bíró (1987), in the early spring and autumn period the eels of Lake Balaton mainly feed on nonbiting midges (Chironomidae) in the pelagic zone, while from May to August their principal food source is constituted by the bleak in the littoral zone.

Infection of paratenic hosts by Anguillicola crassus larvae has been reported by only a few researchers. De Charleroy et al. (1900) experimentally infected common carp Cyprinus carpio with 3rd stage larvae. A. crassus larval infection of paratenic host fish living in natural waters has been studied by Cannaerts (1989), Haenen \& van Banning (1990), Thomas \& Ollevier (1992) and Höglund \& Thomas (1992).

This study, which encompassed a 1 yr period, was aimed at determining which fish species may play a role in the life cycle of Anguillicola crassus in different habitats of Lake Balaton, Hungary. The prevalence and intensity of larval infection of paratenic host fish species were studied, and observations were made on the type of anti-larval host reactions occurring in the different paratenic host species.

\section{MATERIAL AND METHODS}

Sampling. Between September 1991 and September 1992, fishes belonging to different species, of a size suitable for eel food (not exceeding $14 \mathrm{~cm}$ in body length, with the exception of the pike with a mean body length of $24.7 \mathrm{~cm}$ ) were collected by electrofishery in 7 habitats of Lake Balaton in the stony and reedy parts of the littoral zone. The sampling sites were located in the eastern, central and western areas of the $77 \mathrm{~km}$ long and 4 to $8 \mathrm{~km}$ wide (minimum $1.5 \mathrm{~km}$, maximum $14 \mathrm{~km}$ ) lake; thus, the fish caught represented the entire fish population of the littoral region of Lake Balaton.

Characterization of Lake Balaton. This section, which is perhaps a bit more detailed than usual, is needed to understand the unique characteristics of anguillicolosis in Lake Balaton.

As compared to its vast water surface, Lake Balaton is an extremely shallow lake (average water depth: $3.2 \mathrm{~m}$ ), with deviations in water quality between different regions of the lake. In the summer season, the water temperature may be permanently above $20^{\circ} \mathrm{C}$, with temperatures exceeding $25^{\circ} \mathrm{C}$ for some weeks every summer and, in extreme cases, with water temperatures as high as 28 to $31^{\circ} \mathrm{C}$ on some days. In winter the lake is covered by a thick layer of ice. Due to the organic matter load discharged into the lake by the river Zala, the biggest stream running into the lake, the western basin of Lake Balaton is of eutrophic character. The central part of the lake shows a steadily improving water quality, while the eastern basin is oligotrophic, due to the deeper water and the good water quality of the small streams running into it.

In connection with the water quality, the quantity of plankton and, thus, of Anguillicola crassus intermediate hosts (copepods) is much higher in the western than in the eastern basin. In the littoral region, the dominant copepods are Eudiaptomus gracilis and Cýclops spp. (Simonian et al. 1993).

The eel population shows uneven distribution in the lake. Probably because of the better food supply, the eel stock of the western basin is bigger. The eel population of Lake Balaton was estimated in 1991 at about 1000 t. Due to the better than expected results of intensive eel fishing started after the eel mortality of 1991, the current eel population of the lake can be put at 1500 to $2000 \mathrm{t}$. This highly intensive eel stock originates from the 2 to 4 million glass eels regularly introduced into the lake every year except in 1988 to 1990. Regarding the composition of the eel population, in recent years the proportion of larger specimens has increased because of the $3 \mathrm{yr}$ interruption of stocking and the impossibility of transmigration. Transmigration and trapping of eels in the lake's only drain channel (Sió Canal) became impossible as water drainage was suspended during the past dry years. The proportion of older eels will increase within the population because the introduction of eels was prohibited once and for all after the mass eel mortality of 1991 (Molnár et al. 1991).

According to a study of species structure performed by Simonian et al. (1993) between May and October 1991, the fish fauna of Lake Balaton in the littoral region (which is one of the main habitats and feeding areas of the eel) comprises 23 species. Cyprinids represented $92.5 \%$ of the 5256 specimens tested: bleak Alburnus alburnus $38.7 \%$, bitterling Rhodeus sericeus amarus $15.6 \%$, roach Rutilus rutilus $15.1 \%$, rudd Scardinius erythrophthalmus $12.6 \%$, and bream Abramis brama $5.5 \%$. The proportion of percids was $5.8 \%$ while that of fish species belonging to other taxonomic groups constituted $1.8 \%$. The fish species composition of benthic areas under the pelagic zone (which are also considered an eel habitat) is probably different; however, no data are available on such areas.

Methods. The small fish caught by electrofishery were transported live to the laboratory in aerated tanks and kept in aquaria until dissected. Due to the effect of 
season, weather conditions and other factors, the samples collected at the individual sampling times differed in both species composition and specimen number. Thus, many species are included in almost every sample, while others were examined once or on a few occasions only.

The body length of the fish was recorded before dissection. After opening the body cavity, fresh squash preparations were prepared from the entire substance of all inner organs between 2 slides. By examining the preparations in a light microscope, the number of 3rd stage larvae was recorded. Fish specimens not infected by larvae were distinguished from the infected specimens. The infected fish were assigned to one of 3 categories: fish infected only by live larvae, fish infected only by dead larvae, and fish infected by both live and dead larvae.

Squash preparations prepared from fish showing massive infection were microphotographed. Certain heavily infected organs of the fish were fixed in Bouin's solution, sectioned by histological techniques, the sections were stained with haematoxylin and eosin, and microphotographs were taken of them. The host reaction, if any, developing around the larvae was evaluated on the basis of the fresh and histological preparations and the microphotographs.

\section{RESULTS}

The 669 fish specimens collected for processing at 7 sampling sites on a total of 15 occasions during the 12 mo period of study belonged to 20 species. The species most represented in the sample was the bleak $(n=176)$. Thirteen of the fish species were represented by more than 10 specimens in the sample. The results are presented in Table 1 and in Figs. 1, 2 \& 3.

\section{Appearance and identification of the larvae}

Besides 3rd stage Anguillicola crassus larvae, in many cases other helminths (nematodes, trematodes and cestodes) could also be found in the abdominal cavity of the fish examined; however the occurrence of these latter worms was not recorded. With some experience the $A$. crassus larvae were easily distinguishable from other nematodes, first of all by the typical pointed labia located at the worms' anterior end. Infection intensities similar to those found for A. crassus were not observed for any other nematode. By their agile motion the live larvae were easily distinguishable from the dead ones. In some cases the encapsulated larvae showed slow motion, while others did not move at all during a long period of observation. In the classi- fication I adopted these larvae were assigned to the category of 'live encapsulated' and 'dead encapsulated' larvae respectively.

\section{Prevalence and intensity}

All but one of the fish species included in the study proved to be infected by Anguillicola larvae. The prevalence and intensity of infection markedly differed by species. Of the 13 species represented in the sample with at least 10 specimens, ruffe and European catfish showed the highest prevalence of infection $(100 \%)$ followed by river goby $(83 \%)$, white bream (79\%) and bleak (68\%). In the remaining cyprinid species examined in relatively large numbers the prevalence of infection was 36 to $72 \%$. The lowest prevalence of Anguillicola crassus infection (6\%) was demonstrable in pike perch (Fig. 1).

Of the 13 fish species most represented in the sample, ruffe showed the most intensive infection with live larvae (mean intensity: 39.3 3rd stage larvae). European catfish also had an infection of high intensity, with the mean number of live larvae being 26.9 . The third most infected species was river goby (with a mean live larval count of 9.1). In the bleak, the mean number of live 3rd stage larvae was 4.1, while in the other species examined this value was between 1 and 3.7 .

Infection by dead Anguillicola crassus larvae was by far the most expressed in European catfish (with a mean larval count of 188 ) and could be considered high in ruffe (25 larvae), rudd (22.9 larvae), asp (21.3 larvae) and roach (18.5 larvae). The bleak specimens contained 13.2 dead larvae on the average, while in the other species the number of dead larvae was lower (8.5) (Fig. 2).

\section{Miscellaneous infections}

Of the fish species examined in relatively large numbers, in cyprinids the proportion of specimens containing only dead larvae or both dead and live larvae was much higher than in species belonging to other taxonomical entities. Thus, practically all specimens of pumpkinseed (96\%), pike perch $(100 \%)$, river goby $(100 \%)$, European catfish (92\%) and ruffe (100\%) contained live larvae (Fig. 3). Almost all specimens (93\%) of certain cyprinid species (e.g. bitterling) contained only dead larvae, but most other cyprinids also showed a high ratio of infection by dead larvae or a combined infection by both dead and live larvae (rudd 97\%, white bream $96 \%$, roach $85 \%$, bleak $87 \%$ ). The cyprinid species showing the lowest ratio of infection 


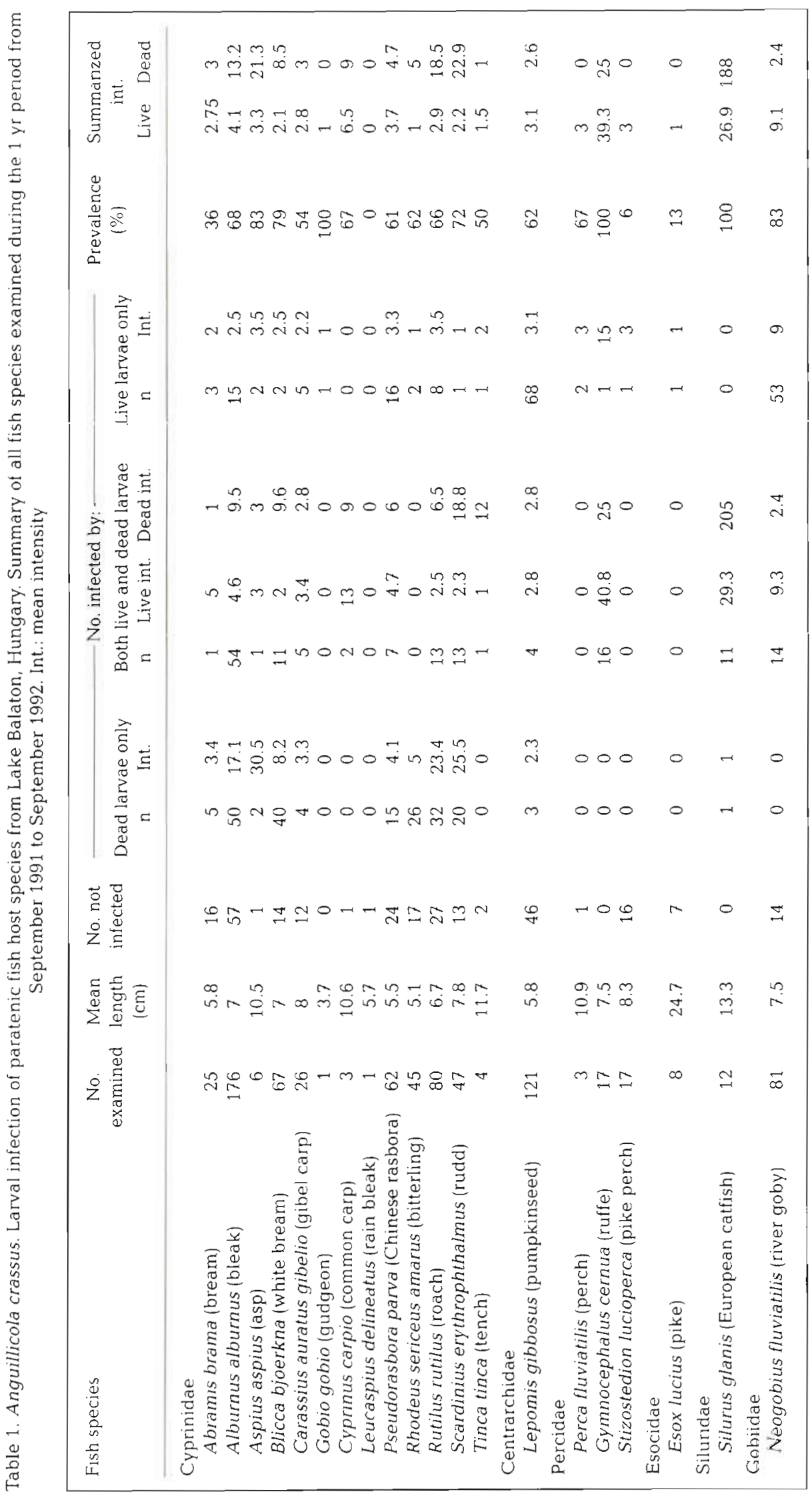


Fig. 1. Anguillicola crassus. Prevalence of infection in paratenic hosts sampled (at least 10 specimens). No. of individuals examined is indicated for each species

infected fish $\square$ non-infected fish

Fig. 2. Anguillicola crassus. Mean intensity of infection in paratenic hosts sampled (at least 10 specimens)
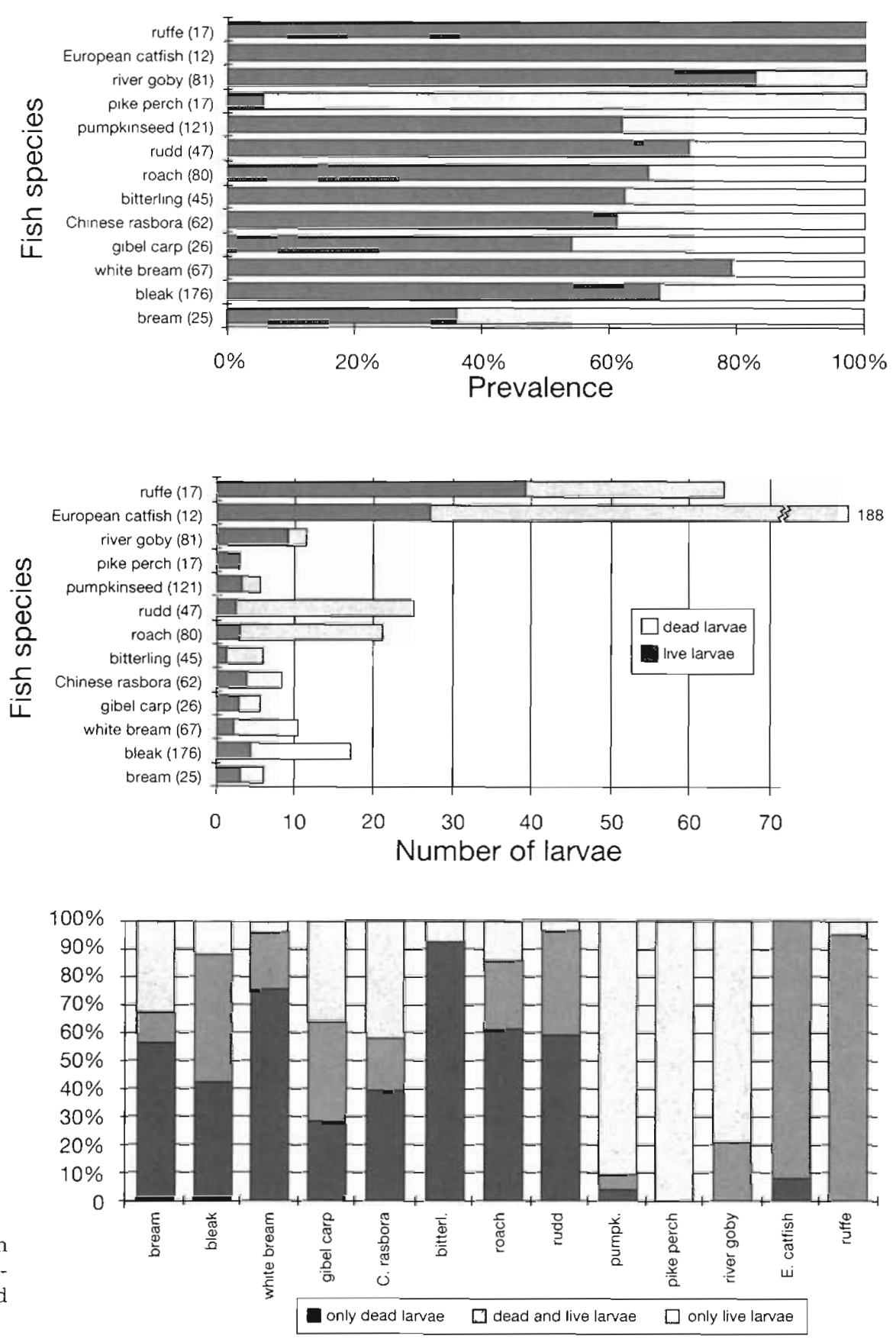

Fig. 3. Anguillicola crassus. Comparison between the different types of infection in infected paratenic hosts sampled (at least 10 specimens)

by dead larvae only or by dead plus live larvae included Chinese rasbora $(58 \%)$, bream $(67 \%)$ and gibel carp $(64 \%)$.

\section{Host reaction in the paratenic hosts}

In the paratenic hosts, the 3rd stage larvae of Anguillicola crassus occurred in the abdominal cavity, in various organs or on the surface thereof. Most larvae could be observed on the outer surface of the intestinal wall or stomach and in the genital organs but some occurred also in the wall of the swimbladder and in the liver. Besides the freely occurring live larvae, in many fish still-living larvae encapsulated by the host organism could also be found (Fig. 4a, b). The capsules formed around the larvae were elongated (Fig. 5a, b) in shape in most cases (primarily in cyprinids and ruffe) and spherical (Fig. 6) at other times (e.g. in European catfish). The structure of encapsulated larvae was still well discernible; however, the larvae no longer showed signs of life (Fig. 7). In many cases, the capsules pre- 


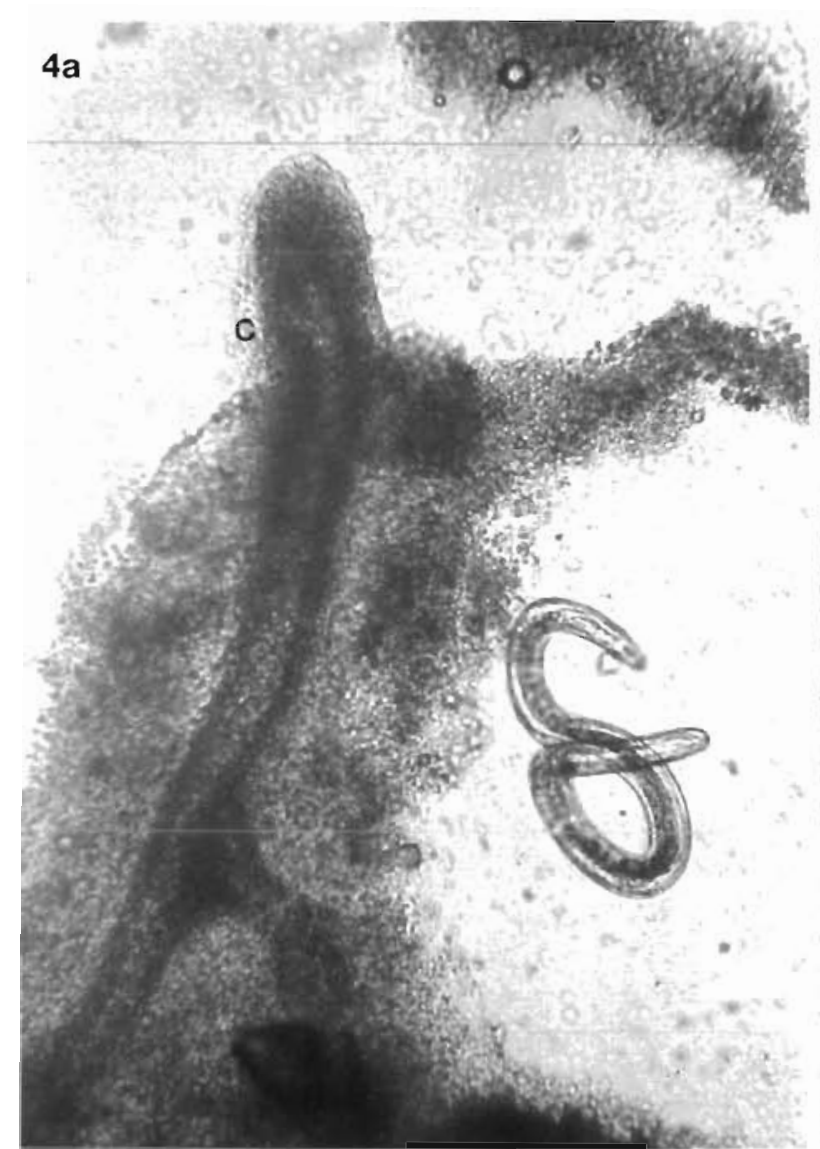

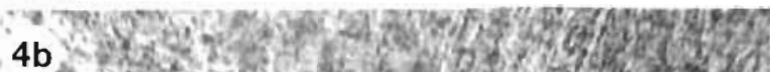

$4 \mathrm{~b}$.

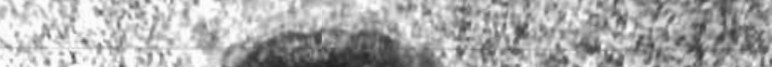

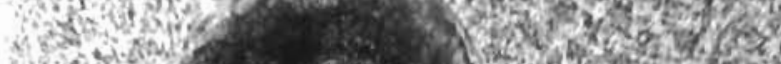

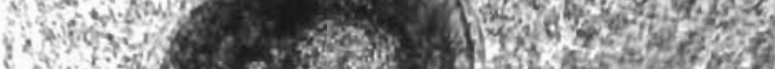

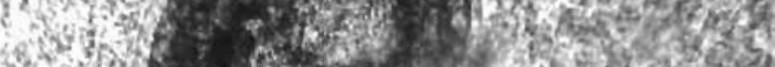

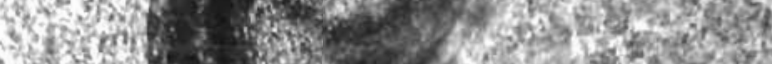

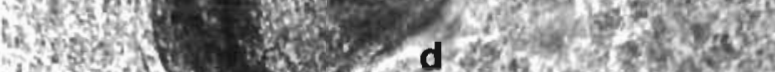

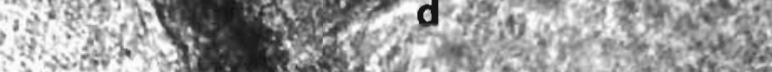

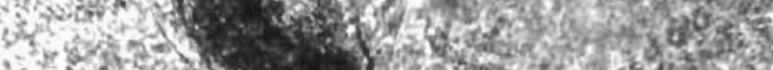

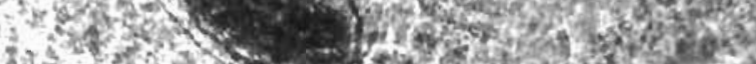

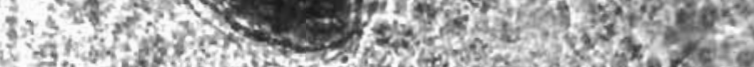

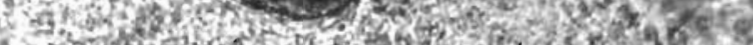

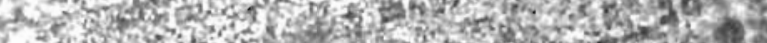

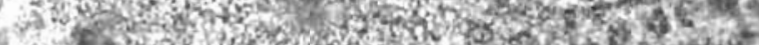

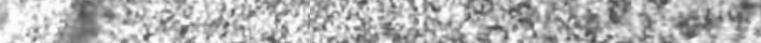

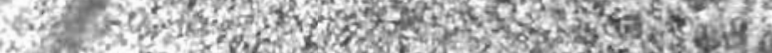

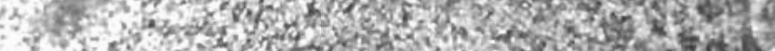

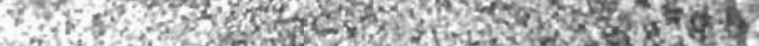

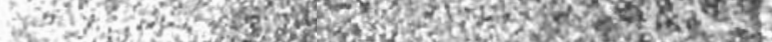

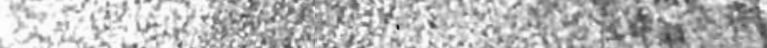

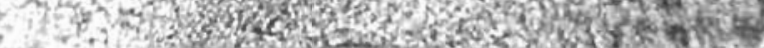

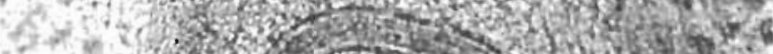

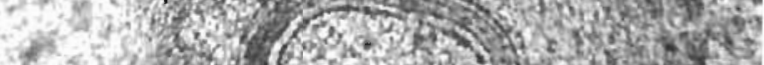

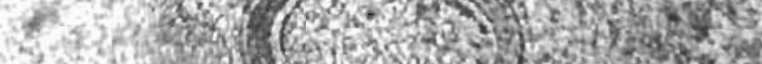

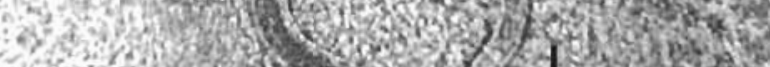
2.t. 4 to An

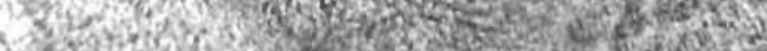

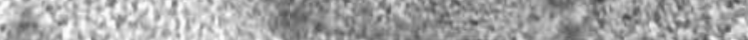

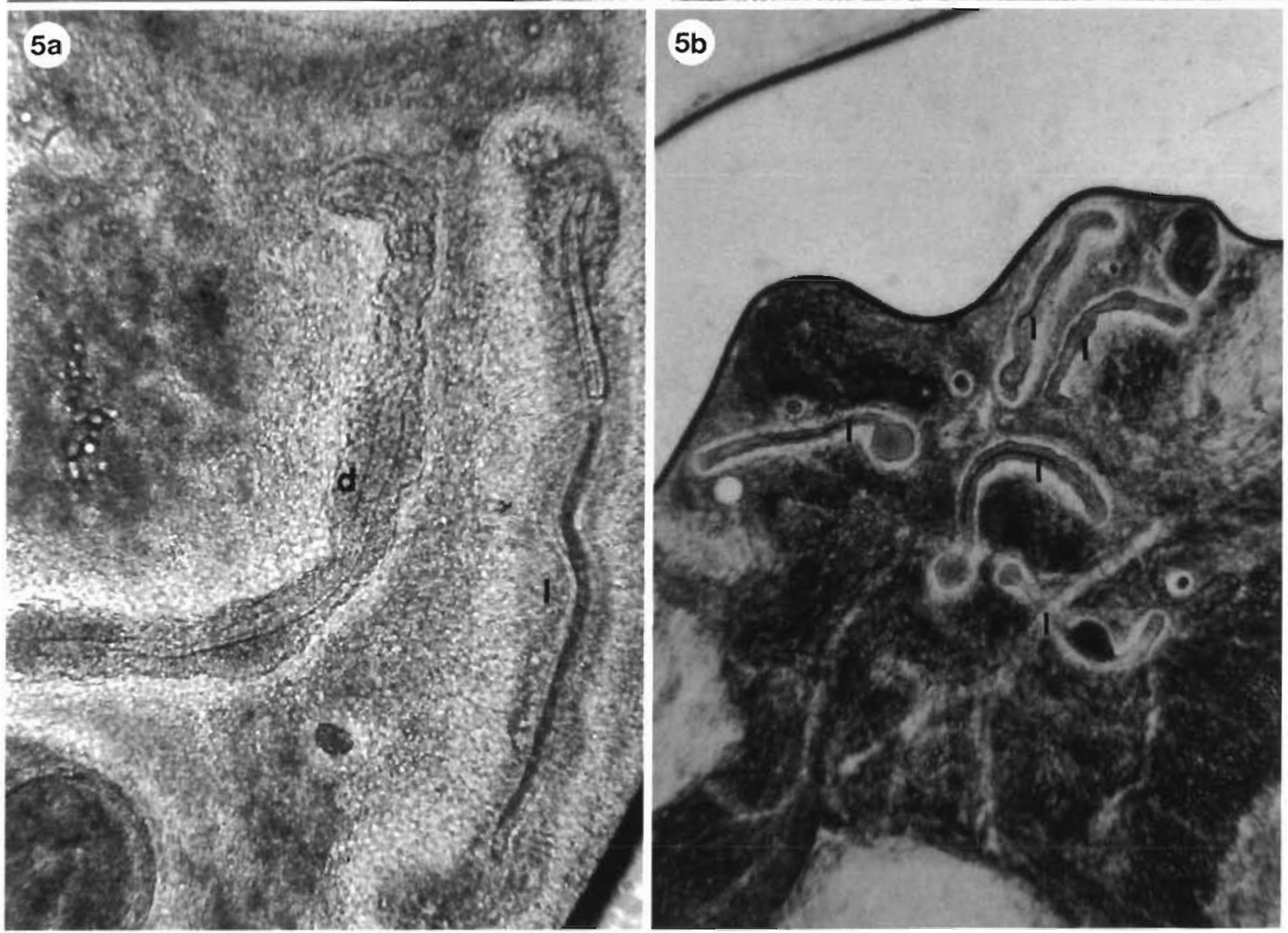

Fig 4 \& 5. Angullucola crassus Fig. 4. (a) Live $\mathrm{L}_{3}$ larva leaving the capsule (c) in paratenuc host. Fresh smear preparation, $\times 126$. (b) Live (l) and dead (d) $L_{3}$ larvae in their capsules in paratenic host. Fresh smear, $\times 135$. Fig. 5. (a) Elongated type of capsules with live (l) and dead (d) $\mathrm{L}_{3}$ larvae in paratenic host Fresh smear, $\times 153$ (b) Elongated type of capsules with larvae (l). Fresh smear, $\times 43$ 

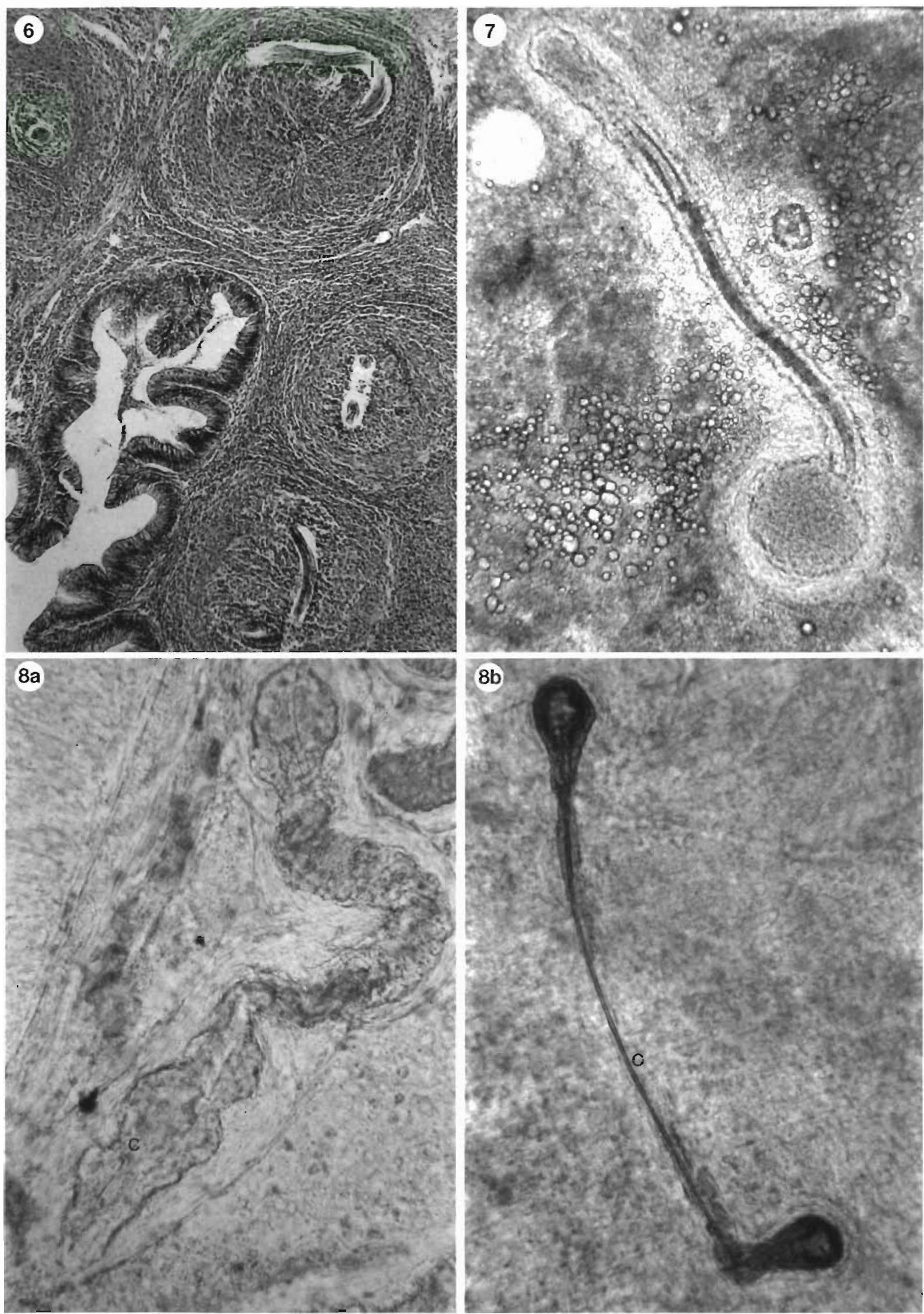

Figs. 6 to 8. Anguillicola crassus. Fig. 6. Spherical capsules (c) around L larvae (1) on European catfish Silurus glanis fingerling's stomach. HE-stained histological section, $\times 135$. Fig. 7. Freshly dead larva in its capsule. The structure is still very discernible. Fresh smear, $\times$ 153. Fig. 8. (a, b) Two types of decomposed encapsulated $\mathrm{L}_{3}$ larvae in paratenic hosts. The cuticles (c) are still recognizable. Fresh smear, $\times 243$ 
sent in the fish contained disrupted larvae with only the cuticle being recognizable (Fig. $8 a, b$ )

\section{DISCUSSION}

Studies aimed at identifying the potential paratenic hosts of Anguillicola crassus have already been conducted. Interestingly enough, no such data are known from Asia, the original habitat of this nematode. Of the European authors dealing with the paratenic hosts of A. crassus, Cannaerts (1989) demonstrated larvae from 2 species (perch Perca fluviatilis, pumpkinseed Lepomis gibbosus), and Haenen \& van Banning (1990) from 5 species (freshwater smelt Osmerus eperlanus, ruffe Gymuncephalus cemuús, perch Perca fluviatilis, pike perch Stizostedion lucioperca, three-spined stickleback Gasterosteus aculeatus). In Belgium, Thomas \& Ollevier (1992) demonstrated larval infection in 16 paratenic host species belonging to 16 different taxonomical entities, and established that the prevalence of larval infection was higher in the physoclist than in the physostome species. Of the species which were found infected in Belgium, $y$ also act as paratenic hosts of $A$. crassus in Lake Balaton: ruffe, pumpkinseed, pikeperch, perch, gudgeon, bleak, rudd, roach and tench. In Lake Balaton, 4 species (carp, gibel carp, bitterling, bream) found negative by Thomas \& Ollevier (1992) were infected by 3rd stage larvae of Anguillicola. Six additional species hitherto not described as paratenic hosts proved to be infected by $A$. crassus larvae in Lake Balaton (asp, white bream, Chinese rasbora, pike, river goby, European catfish). A. crassus infection of high prevalence and intensity has already been described in the littoral zone of the Baltic Sea by Höglund \& Thomas (1992) for black goby Gobius niger, a fish species taxonomically closely related to one of the newly recognized paratenic hosts, river goby.

In Lake Balaton, the bleak serves as the primary food source for eels. According to a 3 yr food structure study performed by Paulovits \& Bíró (1987) between 1982 and 1984 , the bleak represented $93.5 \%$ of all food consumed by eels in the littoral zone and $31.9 \%$ in the pelagic zone. Other fish species had a lower share in the food structure $(1.5 \%$ and $8.1 \%$ in the littoral and the pelagic zone, respectively). Thus, if we compare the results reported by Paulovits \& Bíró (1987) and our own findings presented here, it can be seen that eels of large body size may develop intensive infection with 40 helminths by consuming as few as 10 infected bleak specimens (with a mean live larval count of 4.1). In summer, an infection of such intensity is sufficient to produce swimbladder inflammation or thickening and, possibly, death. An infection of similar intensity may occur after the ingestion of a single ruffe specimen, as in the latter species the mean intensity of infection with live larvae was found to be 39.3 .

Unfortunately, in recent years no one has studied the structure of food consumed by eels in Lake Balaton; thus, there are no data to support our observation that in the stomach of eels caught in the littoral zone the river goby was found in larger numbers than in the 1982 to 1984 survey of Paulovits \& Bíró (1987) (0.3\%). This can be explained by the fact that only in 1970 did the river goby spontaneously establish itself in Lake Balaton (Bíró 1993), and only in the past few years has it become a really common species in the lake. In our opinion, after the bleak the river goby is the second most important species in the feeding of eels and, thus, it plays an important role in the life cycle of Anguillicola crassus in Lake Balaton, the more so as that paratenic host species is characterized by intensive infection by live larvae.

The question often arises why anguillicolosis occurring in Lake Balaton is peculiar, why eel mortalities comparable to that in Lake Balaton have not been reported from other European natural waters in which anguillicolosis emerged earlier, and why mostly eels of large body size died during the Lake Balaton eel mortality. The data presented in this paper furnish a partial answer to these questions. Lake Balaton has an overpopulated eel stock mostly comprising eels of large body size (Molnár et al. 1993). These eels, prevented from transmigrating, mainly feed on bleak, a fish species already showing uniform infection by Anguillicola crassus larvae. Thus, highly intensive A. crassus infection easily develops in the eels.

Some paratenic host species, which play a less important role in the food structure of Lake Balaton eels, may develop very intensive infection. Thomas \& Ollevier (1992) and Höglund \& Thomas (1992) have called attention to the fact that among the intensively infected paratenic hosts benthic species are dominant. This is supported by our observation made in Lake Balaton, where the benthic species (ruffe, river goby and European catfish) are the most intensively infected by live larvae. In the case of European catfish, however, not only the benthic habitude but also the accumulation of larvae resulting from the ingestion of other larva-infected paratenic hosts may have been responsible for the extremely intensive infection.

Although the present results are consistent with those obtained by Thomas \& Ollevier (1992) for fishes from Belgian canals and support their opinion that physoclist fish species are better paratenic hosts than physostome species, we cannot consider the bleak an accidental host, as that species has the biggest share in the eel's food structure in Lake Balaton. The difference between the so-called good paratenic hosts and those less suitable for the larvae depends not so much on 
their infection by 3 rd stage larvae as on the host reaction. Namely, in physoclist fishes the larvae seem to survive longer, and larval death and tissue reactions are less common than in physostome (primarily cyprinid) fishes in which dead larvae are more frequently found besides the live ones.

The ability of larvae to survive in paratenic hosts and the type of host reactions developing in such hosts differs by fish species in Lake Balaton. Still, it cannot be unequivocally stated that cyprinids (primarily the bleak) exhibiting a stronger host reaction are less important in the parasite's life cycle than the pikeperch which does not show a host reaction and was found to contain exclusively live larvae in this study. The fish species playing a role in the parasite's life cycle do not always coincide with those species which ensure the best and longest survival of larvae.

The high adaptability of Anguillicola larvae to new paratenic hosts indigenous only in Europe has probably greatly facilitated the spread of this parasite throughout the European continent. However, the example of Lake Balaton indicates that in the parasite's life cycle in different waters different fish species may act as primary paratenic host, depending on the feeding habits of eels in the given habitat.

Acknowledgements. I thank my project leader, Di Kálmán Molnár, for his useful advice, and Ms Emese Papp and Ms Andrea Jávori for skilful technical assistance. Thanks also to the staff of the Limnological Research Institute of the Hungarian Academy of Sciences for their help in catching the fish used in this study. This work was carried out with financial support from the National Research Fund (OTKA), contract no. T 6035 .

\section{LITERATURE CITED}

Belpaire, C., De Charleroy, D., Grisez, L., Ollevier, F. (1989). Spreading mechanisms of the swimbladder parasite Anguillicola crassus in the European eel Anguilla anguilla and its distribution in Belgium and Europe. European Inland Fishery Advisory Commission (FAO), Working Party on Eel, Porto, Portugal, May 29-June 3, 1989

Bíró, P. (1992). Die Geschichte des Aals (Anguilla anguilla L.) im Plattensee (Balaton). Osterr. Fisch. 45: 197-207

Bíró, P. (1993). Changes in the fish population of Lake Balaton: current status. Halászat 86: 22-24 (in Hungarian)

Boon, J. H., Lokin, C. J. A., Ceusters, R., Ollevier, F. (1989). Some properties of the blood of European eel (Anguilla anguilla) and the possible relationship with Anguillicola crassus infestations. Aquaculture 76: 203-208

Canestri-Trotti, G. (1987). Occurrence of the nematode Anguillicola crassus Kuwahara, Niimi \& Itagaki, 1974 in eels from the Po delta, Italy. Bull. Eur. Ass. Fish Pathol, 7: 109-111

Cannaerts, V. (1989). Interactie van Anguillicola crassus, met enkele typische reservoirgastheren en de eindgastheer Anguilla anguilla M.Sc dissertation, Catholic University of Leuven

Cruz, P., Silva, E., Grazina Freitas, M. S., CarvalhoVarela, M. (1992). First report of Anguillicola crassus in the European eel in Portugal. Bull. Eur. Ass. Fish Pathol. 12: 154-156

De Charleroy, D., Grisez, L., Thomas, K., Belpaire, C., Ollevier, F. (1990). The life cycle of Anguillicola crassus. Dis. aquat. Org. 8: 77-84

Dekker, W., van Willigen, J. (1987). Short note on the distribution and abundance of Anguillicola in The Netherlands. European Inland Fishery Advisory Commission (FAO). Working Party on Eel, Bristol, UK, April 13-16, 1987, p. 1-6

Dupont, F. Petters, A. (1988). Anguilicola, un épızootie plurispécifique en Europe. Apparition d'Anguillicola crassa (Nematoda, Anguillicolidae) chez l'anguille européenne (Anguilla anguilla) en Carmague, sud de la France. Bull. Fr. Pêch. Pisci. 308: 38-41

Egusa, S. (1979). Notes on the culture of the European eel (Anguilla anguilla L.) in Japanese-eel farming ponds. Rapp. P.-v. Réun. Cons. int. Explor. Mer 174: 51-58

Haenen, O. L. M., van Banning, P. (1990). Detection of larvae of Anguillicola crassus (an eel swimbladder nematode) in freshwater fish species. Aquaculture 87: 103-109

Hartmann, S. (1987). Schwimmblasenwürmer beim Aal. Fischer Teichwirt. 38: 2-3

Hellström, A., Ljungberg, O., Bornstein, S. (1988). Anguillicola, en ny alparasit i Sverige. Svensk Veterinartidning. 40: $211-213$

Höglund, J., Thomas, K. (1992). The black goby Gobius niger as a potential paratenic host for the parasitic nematode Anguillicola crassus in a thermal effluent of the Baltic. Dis. aquat. Org. 13: 175-180

Kamstra, A. (1990). Anguillicola in Dutch eelfarms: current state. Int. Revue ges. Hydrobiol. 75: 867-874

Kennedy, C. R., Fitch, D. J. (1990). Colonization, larval survival and epidemiology of the nematode Anguillicola crassus, parasitic in the eel, Anguilla anguilla, in Britain. J. Fish Biol. 36: 117-131

Koie, M. (1988). Parasites in eels, Anguilla anguilla (L.), from eutrophic Lake Esrum (Denmark). Acta Parasitol. Pol. 33: 89-100

Liewes, E. W., Schaminee-Main, S. (1987). Onderzoek aalparasiet vordert. Aquacultuur 2: 5-17

Mellergaard, S. (1988). Alens swommeblaereorm Anguillicola en ny parasit i den europaeiske alebestand. Nord. Aquakultur 4: 50-54

Molnár, K., Székely, Cs., Baska, F. (1991). Mass mortality of eel in Lake Balaton due to Anguillicola crassus infection. Bull. Eur. Ass. Fish Pathol. 11: 211-212

Molnár, K., Baska, F., Csaba, Gy., Glávits, R., Székely, Cs. (1993). Pathological and histopathological studies of the swimbladder of eels Anguilla anguilla infected by Anguillicola crassus (Nematoda: Dracunculoidea). Dis aquat. Org. 15: 41-50

Neumann, W. (1985). Schwimmblasenparasit Anguillicola bei Aalen. Fischer Teichwirt. 36: 322

Paulovits, G., Bíró, P. (1987). Feeding and growth of the eel in Lake Balaton. In: Proc. 29th 'Georgikon' Days, 25-26 August 1987, Keszthely, Hungary, p. 213-226 (in Hungarian with English summary)

Peters, G., Hartmann, F. (1986). Anguillicola, a parasitic nematode of the swimbladder spreading among eel populations in Europe. Dis. aquat. Org. 1: 229-230

Sarti, M., Giorgetti, G., Brisinello, W., Vanelli, M. (1985). A new problem for intensive eel rearing in Italy: Anguillicola australiensis. Proc. Eur. Ass. Fish Pathol. Congr., Montpellier, September 1985, p. 95

Simonian, A., Tátrai, I., Bíró, P., Paulovits, G., Tóth, L., Lakatos, Gy. (1993). Biomass of planktonic crustaceans and the food of young cyprinids in the littoral zone of Lake Balaton. Hydrobiologia (in press) 
Székely, Cs., Láng, M., Csaba, Gy. (1991). First occurrence of Anguillicola crassus in Hungary. Bull. Eur. Ass. Fish Pathol. 11: 162-163

Taı aschewski, H., Moravec, F, Lamah, T, Anders, K. (1987). Distribution and morphology of two helminths recently introduced into European eel populations: Anguillicola crassus (Nematoda, Dracunculoidea) and Paratenuisentis ambiguus (Acantocephala, Tenuisentidae). Dis. aquat. Org. 3: 167-176

Thomas, K., Ollevier, F. (1992). Paratenic hosts of the swimbladder nematode Anguillicola crassus. Dis. aquat. Org. 13: $165-174$

Responsible Subject Editor: W. Körting, Hannover, Germany van Banning, P., Heerman, W, van Willigen, J A. (1985). Anguillicola crassa, een nieuwe aalparasiet in de Nederlandse wateren. Visserij 38: 237-240

van Banning, P., Haenen, O. L. M. (1989). Effects of the swimbladder nematode Anguillicola crassus in wild and farmed eel Anguilla anguilla. In: Perkins, F. O. (ed.) Proc. PAMAQ 3 rd conference, Gloucester Point, USA. Academic Press, New York, p. 317-330

van Willigen, J., Dekker, W. (1989). 1988 update on Anguillicola in Dutch outdoor waters. European Inland Fishery Advisory Commission, Working Party on Eel, Oporto, Portugal, May 30-June 5, 1989, p. 1-8

Manuscript first received: July 5, 1993 Revised version accepted: October 6, 1993 